\title{
Correlates of a lifetime history of sexually transmitted infections among women who have sex with women in Toronto, Canada: results from a cross-sectional internet-based survey
}

\author{
Logie, Carmen H.; Navia, Daniela; Loutfly, Mona R.
}

Version Post-Print/ Accepted Manuscript

Citation Logie, C.H., Navia, D. and Loutfly, M.R. (2015). Correlates of a lifetime (published version) history of sexually transmitted infections among women who have sex with women in Toronto, Canada: Results from a cross-sectional internet-based survey. Sexually Transmitted Infections 91: 278-283. doi:10.1136/sextrans-2014-051745.

Publisher's Statement This article has been accepted for publication in Sexually Transmitted Infections following peer review. The definitive copyedited, typeset version Logie, C.H., Navia, D. and Loutfly, M.R. (2015). Correlates of a lifetime history ofsexually transmitted infections among women who have sex with women in Toronto, Canada: Results from a crosssectional internet-based survey. Sexually Transmitted Infections 91: 278283. is available online at: www.http://sti.bmj.com/content/91/4/278.com 
Original Article

Correlates of a lifetime history of sexually transmitted infections among women who have sex with women in Toronto, Canada: Results from a cross-sectional internet-based survey

Keywords: Sexually Transmitted Diseases; Women; homosexuality, female; Bisexuality; Social Stigma; Social Discrimination

\section{Key messages:}

-There is a need to understand structural factors, such as stigma and discrimination, associated with STI vulnerability among women who have sex with women (WSW)

-STI prevention interventions for WSW should be tailored for women's different sexual practices, paying particular attention to the sexual health needs of bisexual women

-STI prevention strategies for WSW can be integrated into sexual health care and should involve training healthcare providers to better meet the needs of WSW 


\section{ABSTRACT:}

Objectives: Structural drivers of sexually transmitted infections (STI) among women who have sex with women (WSW) have been underexplored. The study objective was to understand socio-

demographic, individual, structural, and sexual health factors associated with a lifetime history of STI among WSW.

Methods: A cross-sectional survey was conducted in 2012 to engage a peer-driven recruitment sample of WSW in Toronto, Canada. Data were collected among a convenience sample of 466 WSW using an online structured interview.

Results: Approximately one-fifth $(\mathrm{n}=89 ; 19.1 \%)$ of participants reported a STI diagnosis history. Participants identifying as bisexual were more likely, and lesbians less likely, to report an STI history than those identifying as queer. In multivariate logistic regression analyses adjusted for socio-demographic variables, STI history was associated with intrapersonal (STI knowledge, HIV/STI risk perceptions), interpersonal (male sex partners in past 3 months, number of lifetime sexual partners), and structural (sexual stigma, history of forced sex, belief health care provider [HCP] uncomfortable addressing sexual orientation) factors as well as sexual health care uptake (ever had STI/HIV test, STI/Pap test in past 2 years). Gender-non-conforming participants were less likely to report a STI history.

Conclusions: This research is among the first to examine intrapersonal, interpersonal and structural factors correlated with a STI history among WSW. Findings highlight the importance of STI prevention strategies for WSW to be tailored to sexual identity, with particular attention to bisexual women's needs. Interventions should connect to sexual health care, address sexual stigma, and train HCP to better meet the needs of WSW. 


\section{INTRODUCTION}

The sexual health of women who have sex with women (WSW) has been described as understudied, in part due to assumptions of limited STI risk [1-4]. Yet a growing body of evidence demonstrates WSW do engage in sexual risk practices, including sex work [1,5-6], injection [5] and non-injection [1,6] substance use, and sex with men [7-10], with low implementation of safer sex practices [4,11-12]. Research illustrates WSW are susceptible to STIs from male and female partners, including Chlamydia, HPV, and herpes [e.g. 1,3-5,10,1216]. In a population-based Canadian study, self-reported STI histories were found among heterosexual women (8\%), lesbians (9\%) and bisexual women (23\%) [8]. Cross-sectional studies

with WSW in the U.S. [1,17] and Australia [5] reported lifetime history of STI rates ranging from $21 \%$ [1] to $53 \%$ [17]. These findings highlight the importance of understanding factors associated with STI vulnerability among WSW.

There is a growing focus on social and structural drivers of sexual health, such as stigma [18-19]. Sexual stigma includes social processes that devalue and limit access to power and opportunities among sexual minority persons, relationships and communities [20]. Sexual stigma dimensions include perceived stigma, awareness of negative social norms, and enacted stigma, such as acts of violence and discrimination [20]. Sexual stigma limits access to sexual health care and HIV/STI prevention, treatment and care [19], and has been associated with HIV/STI vulnerability among men who have sex with men (MSM) [21-22]. There has been less attention to sexual stigma and STI vulnerability among WSW.

Indeed, most studies examining correlates of STI among WSW have focused on sociodemographic and individual level factors, including intrapersonal (e.g. substance use) and interpersonal (e.g. number of sex partners) dimensions [e.g. 1,11,15-16] rather than structural 
dimensions. Several study findings suggest that women with both male and female sexual partners may be at higher risk for STIs than women who have exclusively male or female partners $[7-10,17]$. A recent study revealed sexual assault predicted HIV infection among WSW in Southern Africa [23], underscoring the salience of addressing structural risk contexts.

Our study objective was to understand socio-demographic, individual, structural and sexual health factors associated with a lifetime history of STI among WSW in Toronto, Canada. We also assessed prevalence of self-reported STI among WSW.

\section{METHODS}

\section{Definition of WSW}

The term "WSW" is utilized in sexual health research to be inclusive of women engaging in same sex sexual interactions who may not identify as gay, lesbian, bisexual or queer, although the term is limited in integrating cultural and identity elements [24]. We use WSW to refer to sexually minority women; where we specifically talk about sexual identity we use identity categories (e.g. lesbian, bisexual). A lesbian may be defined as a woman attracted to a woman, and to be bisexual may be defined as a person who is attracted to two sexes or two genders. The term queer conveys multiple meanings in relation to sexual identity, including women attracted to people of multiple genders, transgender and gender-fluid persons ${ }^{2}$.

\section{Study design}

In December 2011-January 2012 we conducted a structured cross-sectional internet-based survey with WSW in Toronto, Canada. Participant inclusion criteria included: adults over 18 years old; 
self-identified WSW, and living in the Greater Toronto Area. Ten WSW were hired as peer recruiters $(\mathrm{PR})$ to recruit study participants.

\section{Participant recruitment and data collection}

Modified peer-driven recruitment [25] was conducted by PR; each PR recruited a predetermined number of participants $(n=25)$ using a combination of strategies (in-person, internet, study flyers). PR were WSW purposively selected due to their lesbian, gay, bisexual, transgender and queer (LGBTQ+) community-based connections, and included service providers, community organizers, and event planners/promoters. By hiring PR reflective of diverse ages, ethnicities and sexual identities, and limiting the number each PR could recruit, we aimed to reduce bias in the sample. We also implemented convenience sampling techniques, sending emails with inclusion criteria and the study purpose to LGBTQ+ agencies, community health centers, HIV/STI service organizations, and ethno-cultural agencies. Participants completed a self-administered 45-60 minute online survey in a self-selected location. The anticipated sample size was 425; this size was calculated as sufficient for logistic regression analyses using $\mathrm{G}^{*}$ Power software (odds ratio: 1.3, $\mathrm{p}<0.05$, power: 0.80). Research ethics approval was granted from Women's College Hospital at the University of Toronto, Canada (WCH REB \#: 2011-0036).

We developed a survey to assess socio-demographic, sexual health, individual and structural correlates of STI. The survey was pilot-tested in a focus group with PR. Focus group feedback was used to modify survey items to enhance survey clarity and appropriateness, and to ensure the socio-demographic information collected was inclusive of sexual and gender diversity (e.g. queer). No identifying information was collected on the survey and participants could opt in to receive a $\$ 20$ gift card honorarium. 


\section{Survey measures}

We assessed socio-demographic variables, including age, income, education, ethnicity, sexual identity, and relationship status. Lifetime histories of STI were self-reported. Intrapersonal measures included perceived HIV and STI risk, based on single items with a 4-point Likert-scale response. The Sexually Transmitted Disease Knowledge Questionnaire (Cronbach's $\alpha=0.77$; range: 0-20) assessed STI knowledge [26]. Interpersonal items assessed lifetime number of sexual partners and gender of sex partners in the past 3 months.

We assessed sexual stigma using Diaz et al.’s Homophobia scale [27]; this scale includes perceived (Cronbach's $\alpha=0.70$; sub-scale range: 4-16) and enacted (Cronbach's $\alpha=0.72$; sub-scale range: 8-32) stigma sub-scales. A single dichotomous item assessed history of forced sex. We assessed barriers to accessing health care, including: time; travel costs; and believing one's HCP was uncomfortable with participants' sexual orientation. We included one item to measure gender non-conformity, being considered masculine in mannerisms/ appearance, with a 4 point Likertscale. To assess sexual health care access, we asked if participants received an HIV, STI (not including HIV) or Pap test ever, and in the past 24 months.

\section{Statistical analyses}

Descriptive analyses were conducted to calculate frequencies, means and standard deviations for variables. We assessed scale reliability using Cronbach's alpha. We conducted multivariate logistic regression analyses to determine correlates of a lifetime STI diagnosis history, an appropriate analytic method for categorical outcomes. First, unadjusted logistic regression analyses were conducted, and following this we conducted logistic regression analyses controlling for sexual orientation and relationship status. Analyses were conducted on nonmissing responses. All analyses were conducted using IBM SPSS 22. 


\section{RESULTS}

\section{Study Population}

Study participant characteristics $(n=466)$ are described in Table 1 .

Table 1 Main characteristics of participants $(n=466)$

\begin{tabular}{|c|c|c|}
\hline Variables $^{\mathrm{a}}$ & Mean (SD) & No of participants $(\%)^{*}$ \\
\hline Age $(n=400)$ & $\begin{array}{l}31.38 \text { (8.12); Median: } 29.0 \\
\text { (Range: } 18-70 \text { ) }\end{array}$ & \\
\hline Annual income & $\begin{array}{l}31,651.32(13,688.56) \\
\text { Median: } 29,000.00\end{array}$ & \\
\hline \multirow{5}{*}{$\begin{array}{l}\text { Sexual Orientation } \\
(\mathrm{n}=417)\end{array}$} & Queer & $193(46.3)$ \\
\hline & Lesbian & $121(29.0)$ \\
\hline & Bisexual & $67(16.1)$ \\
\hline & Gay & $19(4.6)$ \\
\hline & Other & $17(4.1)$ \\
\hline \multirow{6}{*}{$\begin{array}{l}\text { Ethno-racial } \\
\text { identity }(\mathrm{n}=389)\end{array}$} & White/Caucasian & $261(67.1)$ \\
\hline & Black, African Caribbean & $73(18.7)$ \\
\hline & Asian & $16(4.2)$ \\
\hline & South Asian & $16(4.2)$ \\
\hline & Indigenous/Aboriginal & $15(3.8)$ \\
\hline & Multiple ethnicities & $8(2.0)$ \\
\hline \multirow[t]{6}{*}{ Education $(n=419)$} & Less than high school & $4(1.0)$ \\
\hline & High school or equivalent & $29(6.9)$ \\
\hline & Some college/university & $61(14.6)$ \\
\hline & College diploma & $57(13.6)$ \\
\hline & Bachelor degree & $153(36.5)$ \\
\hline & Graduate degree & $115(27.4)$ \\
\hline \multirow[t]{7}{*}{ Relationship status } & Living together (not married) & $140(30.0)$ \\
\hline & Dating (not living together) & $111(23.8)$ \\
\hline & No current partners & $56(12.0)$ \\
\hline & $\begin{array}{l}\text { Polyamourous/multiple } \\
\text { partners }\end{array}$ & $44(9.4)$ \\
\hline & Married & $43(9.2)$ \\
\hline & Casual dating & $43(9.2)$ \\
\hline & Other & $29(6.2$ \\
\hline Number of lifetime & $0-5$ & $88(18.9)$ \\
\hline sexual partners: & $6-10$ & $101(21.7)$ \\
\hline Mean $=14.2(\mathrm{SD}$ & $11-15$ & $172(36.9)$ \\
\hline \multirow[t]{2}{*}{ 11.7) } & $16-20$ & $30(6.4)$ \\
\hline & 21 and higher & $75(16.1)$ \\
\hline
\end{tabular}




\begin{tabular}{|c|c|c|}
\hline \multirow{3}{*}{$\begin{array}{l}\text { Gender of sexual } \\
\text { partners in past } 3 \\
\text { months }\end{array}$} & Male & $118(25.3)$ \\
\hline & Female & $329(70.6)$ \\
\hline & Trans & $67(14.4)$ \\
\hline Lifetime STI & Yes & $89(19.1)$ \\
\hline history & No & $377(80.9)$ \\
\hline \multirow{10}{*}{$\begin{array}{l}\text { STI reported } \\
(n=73)\end{array}$} & HPV and genital warts & $30(6.4)$ \\
\hline & Chlamydia & $19(4.1)$ \\
\hline & Herpes & $16(3.4)$ \\
\hline & HIV & $6(1.4)$ \\
\hline & Don't know /don't remember & $3(0.6)$ \\
\hline & Trichomoniasis & $1(0.2)$ \\
\hline & Pubic lice & $1(0.2)$ \\
\hline & Gonorrhea & $1(0.2)$ \\
\hline & Hepatitis C & $1(0.2)$ \\
\hline & Molluscum contagiosum & $1(0.2)$ \\
\hline $\begin{array}{l}\text { Currently living } \\
\text { with STI }\end{array}$ & Currently living with STI & $24(5.2)$ \\
\hline \multirow[t]{2}{*}{ Received STI test } & Ever & $312(67.0)$ \\
\hline & Past 24 months & $248(53.2)$ \\
\hline \multirow[t]{2}{*}{ Received HIV test } & Ever & $278(59.7)$ \\
\hline & Past 24 months & $212(45.5)$ \\
\hline Received Pap test & Past 24 months & $332(71.2)$ \\
\hline History of lifetime & Yes & $173(41.7)$ \\
\hline $\begin{array}{l}\text { sexual assault } \\
(\mathrm{n}=415)\end{array}$ & No & $242(58.3)$ \\
\hline Perceived as & No & $306(65.7)$ \\
\hline $\begin{array}{l}\text { gender non- } \\
\text { conforming }\end{array}$ & Yes & $160(34.3)$ \\
\hline \multicolumn{2}{|c|}{$\begin{array}{l}\text { Believe healthcare providers were not comfortable } \\
\text { with their sexual orientation }\end{array}$} & $64(13.7)$ \\
\hline \multicolumn{3}{|c|}{${ }^{a}{ }_{n}=466$ unless otherwise specified } \\
\hline \multicolumn{3}{|c|}{${ }^{b}$ Participants could select more than 1 response } \\
\hline \multicolumn{3}{|c|}{ The mean age was 31.4 (SD: 8.1 ), the mean annual income was $\$ 31,651 \mathrm{CAD}(\mathrm{SD}: 13,688)$ and } \\
\hline \multicolumn{3}{|c|}{$34 \%$ self-categorized as an ethno-racial minority. Among participants, $46 \%$ self-categorized as } \\
\hline \multicolumn{3}{|c|}{ queer, $29 \%$ as lesbian and $16 \%$ as bisexual, $5 \%$ gay and $4 \%$ other. Participants reported a mean } \\
\hline \multicolumn{3}{|c|}{ of 14.2 (SD 11.7) lifetime sexual partners. Approximately one-fifth (19.1\%) of participants } \\
\hline \multicolumn{3}{|c|}{ reported a lifetime STI history, of these 5\% reported currently living with an STI. Histories of } \\
\hline STI were highest & nong bisexual (38\%), follow & eer $(21 \%)$, lesbian $(10 \%)$, and gay $(5 \%$ \\
\hline
\end{tabular}


question describing the STI they were diagnosed with; 73/89 completed this information. The most common STI reported among participants included: HPV and genital warts $(n=30,6 \%)$, Chlamydia $(n=19,4 \%)$, Herpes $(n=16,3 \%)$ (most participants did not differentiate between oral/genital herpes), and HIV ( $\mathrm{n}=6,1 \%)$.

\section{Correlates of having a lifetime STI history}

Results from logistic regression analyses are presented below in Table 2.

Table 2 Univariate and multivariate logistic modeling of factors associated with a lifetime history of STI $(n=466)$

\begin{tabular}{|c|c|c|c|c|c|}
\hline Variables & & $\begin{array}{l}\text { Unadjusted } \\
\text { univariate logistic } \\
\text { regression } \\
\text { analyses, OR } \\
(95 \% \mathrm{CI})\end{array}$ & $\mathrm{p}$ value & $\begin{array}{l}\text { Adjusted } \\
\text { multivariate } \\
\text { logistic regression } \\
\text { analyses } 1, \text { OR } \\
(95 \% \mathrm{CI})\end{array}$ & $\begin{array}{l}\mathrm{p} \\
\text { value }\end{array}$ \\
\hline \multirow{16}{*}{$\begin{array}{l}\text { Socio- } \\
\text { demographic } \\
\text { Variables }\end{array}$} & Age & $1.03(0.99,1.09)$ & 0.09 & & \\
\hline & Education & $1.08(0.46,2.53)$ & 0.87 & & \\
\hline & Income & $1.00(1.00,1.00)$ & 0.22 & & \\
\hline & $\begin{array}{l}\text { Ethnicity (person of color } \\
\text { vs. white) } \\
\text { Sexual orientation: }\end{array}$ & $0.80(0.47,1.36)$ & 0.41 & & \\
\hline & Queer (ref) & 1 & & & \\
\hline & bisexual & $2.42(1.37,4.27)$ & 0.002 & & \\
\hline & lesbian & $0.43(0.22,0.84)$ & 0.01 & & \\
\hline & gay & $0.21(0.03,1.62)$ & 0.14 & & \\
\hline & $\begin{array}{l}\text { Transgender or gender } \\
\text { queer }\end{array}$ & $0.39(0.15,1.01)$ & 0.05 & & \\
\hline & $\begin{array}{l}\text { Relationship status: } \\
\text { Multiple partners } \\
\text { (ref) }\end{array}$ & & & & \\
\hline & other & $0.56(0.19,1.59)$ & 0.27 & & \\
\hline & married & $0.60(0.24,1.51)$ & 0.28 & & \\
\hline & cohabitating & $0.31(0.14,0.67)$ & 0.001 & & \\
\hline & dating & $0.32(0.14,0.74)$ & 0.002 & & \\
\hline & casual dating & $0.68(0.27,1.67)$ & 0.40 & & \\
\hline & $\begin{array}{l}\text { no current } \\
\text { partners }\end{array}$ & $0.29(0.11,0.77)$ & 0.01 & & \\
\hline \multirow{3}{*}{$\begin{array}{l}\text { Intrapersonal } \\
\text { factors }\end{array}$} & Perception of HIV risk & $2.20(1.42,3.41)$ & 0.0004 & $2.28(1.42,3.66)$ & 0.007 \\
\hline & Perception of STI risk & $1.86(1.32,2.61)$ & 0.0003 & $1.88(1.28,2.76)$ & 0.006 \\
\hline & STI knowledge & $1.10(1.02,1.19)$ & 0.01 & $1.08(1.00,1.17)$ & 0.04 \\
\hline Interpersonal & Male sex partners in past & $4.00(2.46,6.52)$ & 0.00002 & $3.52(2.06,6.02)$ & 0.004 \\
\hline
\end{tabular}




\begin{tabular}{|c|c|c|c|c|c|}
\hline \multirow[t]{2}{*}{ Factors } & \multicolumn{5}{|l|}{3 months } \\
\hline & $\begin{array}{l}\text { Number of lifetime } \\
\text { sexual partners }\end{array}$ & $1.03(1.01,1.04)$ & 0.01 & $1.03(1.01,1.04)$ & 0.01 \\
\hline Structural & Enacted sexual stigma & $5.64(1.08,29.43)$ & 0.04 & $6.50(1.10,38.31)$ & 0.04 \\
\hline \multirow[t]{5}{*}{ Factors } & History of forced sex & $2.18(1.35,3.53)$ & 0.002 & $2.38(1.44,3.93)$ & 0.003 \\
\hline & Perceived sexual stigma & $2.08(1.12,3.87)$ & 0.02 & $2.09(1.08,4.03)$ & 0.03 \\
\hline & $\begin{array}{l}\text { Barrier: Belief HCP not } \\
\text { comfortable with sexual } \\
\text { orientation }\end{array}$ & $2.00(1.10,3.63)$ & 0.02 & $1.97(1.06,3.67)$ & 0.03 \\
\hline & $\begin{array}{l}\text { Perceived as gender non- } \\
\text { conforming (e.g. } \\
\text { butch/stud/masculine) }\end{array}$ & $0.59(0.46,0.76)$ & 0.00007 & $0.58(0.45,0.76)$ & 0.001 \\
\hline & $\begin{array}{l}\text { Barrier: don't have the } \\
\text { time }\end{array}$ & $1.71(1.03,2.84)$ & 0.04 & $1.48(0.88,2.49)$ & 0.14 \\
\hline Sexual & Ever had an STI test & $4.27(1.66,10.99)$ & 0.002 & $3.89(1.49,10.14)$ & 0.01 \\
\hline Health Care & Ever had an HIV test & $2.95(1.49,5.82)$ & 0.003 & $2.76(1.38,5.52)$ & 0.004 \\
\hline \multirow[t]{3}{*}{ Access } & Pap test in last 2 years & $2.76(1.48,5.17)$ & 0.001 & $2.38(1.24,4.56)$ & 0.01 \\
\hline & $\begin{array}{l}\text { Had STI test in past } 2 \\
\text { years }\end{array}$ & $2.36(1.44,3.87)$ & 0.001 & $2.02(1.20,3.39)$ & 0.01 \\
\hline & $\begin{array}{l}\text { Had HIV test in past } 2 \\
\text { years }\end{array}$ & $1.61(1.01,2.56)$ & 0.04 & $1.33(0.82,2.16)$ & 0.24 \\
\hline
\end{tabular}

${ }^{1}$ Adjusted for sexual orientation and relationship status

OR: Odds ratio

Note: $83.1 \%$ correct classification of cases; Hosmer-Lemeshow $\left(\chi^{2}=7.90, \mathrm{p}=0.44\right) ; \mathrm{R}^{2}=0.17$ (Cox \& Snell), $\mathrm{R}^{2}=0.28$ (Nagelkerke)

As detailed in Table 2, STI history was correlated with sexual orientation and relationship status, with bisexual participants over twice as likely, and lesbians approximately half as likely, to report an STI history than those identifying as queer. Participants who were cohabitating, dating or had no current partners were less likely to report an STI history than those with multiple partners. No other socio-demographic variables were significantly correlated with a history of STI.

In multivariate logistic regression analyses controlling for socio-demographic variables, STI history was associated with intrapersonal factors including higher HIV risk perceptions, STI risk perceptions and STI knowledge scores. Interpersonal factors associated with an STI history included lifetime number of sexual partners. Participants who reported having male sex partners in the past 3 months were 3.5 times more likely to report a STI history than those with no recent male sex partners.

There were several structural variables associated with a STI history. Notably, 
participants who experienced enacted sexual stigma were 6.5 times more likely, and those who experienced perceived sexual stigma were twice as likely, to report a STI history. Those with a history of forced sex were over twice as likely to have had an STI. Participants who reported being gender non-conforming were almost half as likely to report a STI history.

Health care experiences were also significant correlates of a lifetime STI history. Having had an STI was associated with the belief that one's HCP was not comfortable with one's sexual orientation. STI history was correlated with sexual health care uptake: participants who reported ever having had an STI test were over 3 times as likely, and those who had ever had an HIV test over twice as likely, to report having had an STI. STI histories were over twice as frequently reported among participants who had received a Pap test or STI test in the past 2 years.

\section{DISCUSSION}

Our study is among the first to investigate individual, structural and sexual health correlates of a history of STI among WSW. Results indicate that almost one-fifth of participants have a lifetime STI history. Participants with a bisexual identity were more likely, and lesbians less likely, to report an STI history than than those identifying as queer. Controlling for socio-demographics, STI history was associated with intrapersonal (STI knowledge, HIV/STI risk perceptions), interpersonal (male sex partners in past 3 months, number of lifetime sexual partners), and structural (perceived/enacted sexual stigma, history of forced sex, belief HCP were uncomfortable addressing sexual orientation) factors as well as sexual health care uptake (ever had STI/HIV test, receiving STI/Pap tests in past 2 years). Gender-non-conforming participants were less likely to report a STI history. Our study identifies an important set of social-ecological factors associated with a lifetime history of STI among WSW. Social ecological frameworks highlight multi-level (intra/interpersonal, social, structural) contexts of population health [19]. 
Our finding of a $20 \%$ lifetime history of STI among WSW corroborates lifetime rates of STI in previous cross-sectional work with targeted WSW samples in the US [1]. Similar to prior research, we found that having male sexual partners in the past 3 months was associated with a STI history [7-10,15]. Our findings are similar to Steele et al.'s [8] Canadian population-based study findings in two ways: we also found higher self-reported STI rates among bisexuals than lesbians, and similar self-reported STI history rates $(\sim 10 \%)$ among lesbians. However selfreported STI rates among bisexuals were higher in our sample (38\%) than in Steele et al.'s study (21\%) [8]; this could be due to our non-random sample. Steele et al. recognized the categories of homosexual/bisexual were not inclusive of all WSW and there was likely underreporting of STI among WSW [8]. We found similar prevalence of Chlamydia (4\%) [5], gonorrhea $(0.2 \%)$ [11] and genital herpes/HSV-2 (3\%) among WSW as previous studies [5,9-11,15). Our HPV prevalence $(6 \%)$ was lower than reported rates $(13 \%)$ based on HPV DNA testing in US studies with WSW [14]. This difference in self-reported vs. DNA tested HPV prevalence highlights the possibility of low HPV testing rates among WSW in Toronto.

We did not locate other studies that measured associations between STI knowledge, HIV/STI risk perceptions, and STI history among WSW. Having experienced a STI could enhance one's awareness about HIV/STI risk and could increase STI knowledge. The crosssectional, quantitative study design precludes understanding of the nature of this association. Our finding that interpersonal factors, including lifetime sexual partners and male partners, were associated with a history of STI corroborates prior research (e.g. 1,11,15-16). We found gender non-conforming women are less likely to have a history of STI, suggesting the need to better understand sexual practices among WSW with more masculine gender presentation. While onequarter of participants reported recent sex with a male partner only $16 \%$ identified as bisexual, corroborating research that highlights discrepancies between sexual identity and practices [24]. 
One of the most unique findings of this study is the association between sexual stigma (enacted, perceived) and STI history. To our knowledge no studies have measured this association among WSW, although sexual stigma has been identified as a structural risk factor for STI with MSM [e.g. 21-22]. Our finding that forced sex was associated with STI history corroborates prior research among WSW in Southern Africa [23], suggesting the importance of assessing sexual violence as a structural risk factor. Associations between accessing sexual health care access and a history of STI point to the salience of integrating sexual health services into general medical treatment.

There are several limitations to our study. Generalizabilty is limited due to the nonprobability sample. Our sample includes one-third ethno-racial participants-lower than $47 \%$ in Toronto's population [28]. We oversampled persons with bachelor degrees: $65 \%$ in the study in comparison with 33\% in Toronto's general population [29]. This may be due to the online survey design biased to include persons with internet access [30]. We could not assess chronicity or causality due to the cross-sectional study design. Self-reported STI could result in underreporting. Clarifying STI diagnoses timeframes would strengthen findings. Associations between health care and STI could be confounders of the relationship between health care utilization and STI testing. Finally, social desirability bias could influence sexual risk responses. These limitations point to the need for future studies to use more representative samples of WSW, biologic STI outcomes, and longitudinal designs to assess the trajectory of STI and social ecological factors. Despite these limitations, we are the first study to assess associations between sexual stigma and other structural factors and STI history among WSW. Understanding the role of sexual stigma and sexual health care in STI prevention among WSW is an important area for future research.

Study findings suggest STI prevention strategies for WSW should be multi-level and tailored to address the diversity of sexual practices among WSW [12]. It is important to enhance 
STI knowledge and access to sexual health care. Interventions to challenge sexual stigma must be implemented at community and institutional levels. Training HCP about WSW is essential to enhancing sexual health among WSW. Effective STI prevention strategies with WSW can benefit from a social ecological approach [19] that conceptualizes social and structural contexts of women's sexual health.

Funding This study was funded by the Canadian Institutes of Health Research (CIHR) Social Research Centre in HIV Prevention. The funders played no role in study design, analysis or interpretation of results.

The Corresponding Author has the right to grant on behalf of all authors and does grant on behalf of all authors, an exclusive licence on a worldwide basis to the BMJ Publishing Group Ltd to permit this article to be published in STI and any other BMJPGL products and sub-licences such use and exploit all subsidiary rights, as set out in our licence.

Author Contributions C. Logie conceptualized and led the study, analysis and writing; D. Navia contributed to the literature review; M. Loutfy contributed to study design and interpretation of results. 


\section{REFERENCES}

1. Bauer GR, Welles S. Beyond assumptions of negligible risk: sexually transmitted diseases and women who have sex with women. Am J Public Health 2001:91:1282-6.

2. Logie C. (Where) do queer women belong? Theorizing intersectional and compulsory heterosexism in HIV research. Critical Public Health 2014. http://dx.doi.org/10.1080/09581596.2014.938612

3. Marrazzo JM. Sexually transmitted infections in women who have sex with women: who cares? Sex Transm Infect 2000;76:330-2.

4. Pinto V, Tancredi M, Neto A, et al. Sexually transmitted disease/HIV risk behaviour among women who have sex with women. AIDS 2005:19:S64-9.

5. Fethers K, Marks C, Mindel A, et al. Sexually transmitted infections and risk behaviours in women who have sex with women. Sex Transm Inf 2000;76:345-9.

6. Lyons T, Kerr T, Duff P, et al. Youth, violence and non-injection drug use: nexus of vulnerabilities among lesbian and bisexual sex workers. AIDS Care 2014[Epub ahead of print]:15.

7. Bauer GR, Jairam JA, Baidoobonso SM. Sexual health, risk behaviors, and substance use in heterosexual-identified women with female sex partners: 2002 US National Survey of Family Growth. Sex Transm Dis 2010;37:531-7.

8. Steele LS, Ross LE, Dobinson C, et al. Women's Sexual Orientation and Health: Results from a Canadian Population-Based Survey. Women Health 2009;49:353-67.

9. Tao G. Sexual orientation and related viral sexually transmitted disease rates among US women aged 15 to 44 years. Am J Public Health 2008;98:1007-9.

10. Xu F, Sternberg MR, Markowitz LE. Women who have sex with women in the United States: prevalence, sexual behavior and prevalence of herpes simplex virus type 2 infection-results from national health and nutrition examination survey 2001-2006. Sex Transm Dis 2010:37:407-13.

11. Bailey JV, Farquhar C, Owen C, et al. Sexually transmitted infections in women who have sex with women. Sex Transm Infect 2004;80:244-6.

12. Schick V, Rosenberger JG, Herbenick D, et al. Sexual behaviour and risk reduction strategies among a multinational sample of women who have sex with women. Sex Transm Infect 2012;88: 407-12.

13. Bailey JV, Kavanagh J, Owen C, et al. Lesbians and cervical screening. Br J Gen Pract. 2000;50:481-2.

14. Marrazzo JM, Koutsky LA, Kiviat NB, et al. Papanicolaou test screening and prevalence of genital human papillomavirus among women who have sex with women. Am J Public Health 2001;91:947-52.

15. Marrazzo JM, Stine K, Wald A. Prevalence and risk factors for infection with herpes simplex virus type-1 and -2 among lesbians. Sex Transm Dis 2003;30:890-5.

16. Singh D, Fine DN, Marrazzo JM. Chlamydia trachomatis Infection Among Women Reporting Sexual Activity With Women Screened in Family Planning Clinics in the Pacific Northwest, 1997 to 2005. Am J Public Health 2011;101:1284-90.

17. Muzny CA, Sunesara IR, Martin DH, Mena LA. Sexually transmitted infections and risk behaviors among African American women who have sex with women: does sex with men make a difference? Sex Transm Dis 2011;38:1118-1125.

18. Auerbach JD, Parkhurst JO, Caceres CF: Addressing social drivers of HIV/AIDS for the longterm response: conceptual and methodological considerations. [Review]. Glob Public Health 2011;6:S293-S309.

19. Baral S, Logie C, Grosso A, Wirtz A, Beyrer C. Modified social ecological model: a tool to visually represent the risks and risk contexts of HIV epidemics. BMC Public Health 2013;13: 482.

20. Herek GM. Confronting sexual stigma and prejudice: Theory and practice. J Soc Issues 2007; 63:905-25. 
21. Bruce D, Ramirez-Valles J, Campbell RT. Stigmatization, substance use and sexual risk behavior among Latino Gay and Bisexual Men and Transgender Persons. J Drug Issues 2008;38:235-60.

22. Yi H, Sandfort TGM, Shidlo A. Effects of disengagement coping with HIV risk on unprotected sex among HIV-negative gay men in New York City. Health Psychol 2010;29:205-14.

23. Sandfort TGM, Baumann LRM, Matebeni Z, Reddy V, Southey-Swartz I. Forced sexual experiences as risk factor for self-reported HIV infection among southern African lesbian and bisexual women. PLoS One 2013;8:e53552.

24. Young RM, Meyer IH. The trouble with "MSM" and "WSW": Erasure of the sexual-minority person in public health discourse. Am J Public Health, 2005;95:1144-9.

25. Magnani R, Sabin K, Saidel T, Heckathorn D. Review of sampling hard-to-reach and hidden populations for HIV surveillance. AIDS 2005;19:S67e72.

26. Jaworski, B.C. \& Carey, M.P.. Development and psychometric evaluation of a self-administered questionnaire to measure knowledge of sexually transmitted disease. AIDS Behav 2007;11:55774.

27. Diaz RM, Ayala G, Bein E, Henne J, Marin B. The impact of homophobia, poverty and racism on the mental health of gay and bisexual Latino men: Findings from 3 US cities. Am J Public Health;2001;91:927-32.

28. City of Toronto. Toronto's Racial Diversity. 2013 Available at: http://www.toronto.ca/toronto facts/diversity.htm. Accessed: 1 September 2013.

29. City of Toronto. 2011 National Household Survey: Labour Force, Education, Place of Work, Commuting and Mobility. Available at:

www.toronto.ca/demographics/pdf/nhs_backgrounder.pdf. Accessed: 1 September 2013.

30. Meyer IH, Wilson PA. Sampling lesbian, gay and bisexual populations. J Couns Psychol 2009; 56:23-31. 


\section{Web Appendix}

A lesbian, may be defined as a woman attracted to a woman, and to be bisexual may be defined as a person who is attracted to two sexes or two genders. The term queer conveys multiple meanings in relation to sexual identity: an umbrella term to refer to all sexually and gender people, a person attracted to multiple genders or a political category that advocates breaking binary thinking and seeing both sexual orientation and gender identity as potentially fluid. For example, the term lesbian or the term heterosexual may not reflect the identities of women with partners who transition from women to transgender men, or women with transgender or gender-fluid partners.

Key References:

Beemyn, Brett, and Mickey Eliason, eds. Queer studies: A lesbian, gay, bisexual, \& transgender anthology. NYU Press, 1996.

Eliason, Michele J., and Robert Schope. "Shifting sands or solid foundation?

Lesbian, gay, bisexual, and transgender identity formation." The health of sexual minorities. Springer US, 2007. 3-26.

Halberstam, Judith. In a queer time and place: Transgender bodies, subcultural lives. NYU Press, 2005.

James, Christopher. "Denying complexity: The dismissal and appropriation of bisexuality in queer, lesbian, and gay theory." Queer studies: A lesbian, gay, bisexual, and transgender anthology (1996): 217-240.

Khayatt, Didi. "Toward a queer identity." Sexualities 5.4 (2002): 487-501. 